\title{
Colorectal Undifferentiated Carcinoma
}

National Cancer Institute

\section{Source}

National Cancer Institute. Colorectal Undifferentiated Carcinoma. NCI Thesaurus. Code C43591.

An invasive malignant epithelial tumor that arises from the colon or rectum. There is no morphologic, immunophenotypic, or molecular biological evidence of glandular or squamous differentiation. 